\title{
Moda: tecendo outras possibilidades na construção das identidades de gênero
}

\author{
Maíra Arcoverde
}

\begin{abstract}
Resumo: Desde que o ato de vestir passou a engendrar um sistema efêmero de constantes mudanças hoje chamado moda, a roupa tornou-se uma linguagem não-verbal por meio da qual as pessoas comunicam sua posição na sociedade e suas relações entre si. No contexto deste trabalho, analisarei a moda dialogando com estudos históricos e sociológicos que possam fornecer pistas para entender como a roupa corroborou com a construção e manutenção de um discurso binário masculino-feminino como pré-discursivo, e como a própria produção discursiva dos gêneros teceu roupas que lhe servissem. $\mathrm{O}$ tensionamento do texto, entretanto, é de mostrar que dentro da própria trama da moda e da matriz binária dos gêneros é possível encontrar fissuras para subverter a lógica hegemônica e (des)construir as formas do vestir para além das linhas que circunscrevem as fronteiras das construções culturais.
\end{abstract}

Palavras-chave: Moda; Gênero; Reiteração; Subversão.

Abstract: Since the act of dressing started to engender an ephemeral system of constant change now called fashion, the garment has become a nonverbal language through which people communicate their position within society and their relations among themselves. Within the context of this work, I will analyze fashion dialoguing with historical and sociological studies that can provide clues to understanding how garment has corroborated to the construction and maintenance of a binary male-female discourse as pre-discoursive, and how the discoursive production of the genders itself has woven clothes that fit it. The tension of the text thus lies in showing that within the fashion fabric and the binary gender matrix themselves is it possible to find gaps to subvert the hegemonic logic and (de)construct the ways of dressing beyond the lines that circumscribe the boundaries of the cultural constructions.

Key words: Fashion; Gender; Reiteration; Subversion.

Resumen: Desde que el acto de vestirse empezó a engendrar un sistema efímero de continúo cambio ahora llamado moda, la ropa se ha convertido en un lenguaje no verbal a través del cual las personas comunican su posición en la sociedad y sus relaciones entre sí. En el contexto de este artículo, analizaré la moda dialogando con los estudios históricos y sociológicos que puedan proporcionar pistas para entender cómo la ropa corroboró con la construcción y mantenimiento de un discurso binario hombre-mujer como pre-discursivo, y cómo la propia producción discursiva de los géneros tejió ropas que les sirviesen. La tensión del texto, sin embargo, es mostrar que dentro de la propia trama de la moda y de la matriz binaria de los géneros es posible encontrar fisuras para subvertir la lógica hegemónica y (de) construcción de formas de vestir para más allá de las líneas que delimitan las fronteras de las construcciones culturales. Palabras clave: Moda; Género; Reiteración; Subversión.

De maneira geral, pensar no termo "moda" significa, dentro da história da indumentária, pensar no fenômeno nascido entre o final da Idade Média e início da Idade Moderna (Renascimento) nas sociedades ocidentais. Aqui se iniciam os mecanismos de temporalidade e constante mudança que caracterizam o vestuário até nosso tempo, cuja causa historiadorxs da área associam aos anseios das classes em ascensão em copiar a aristocracia. Mais além, é fundamental frisar que foi durante o mesmo período que pudemos observar o início da divisão binária dos gêneros através da roupa, divisão tal que também foi força motriz das mudanças na indumentária.

1 Graduada em Têxtil e Moda pela Universidade de São Paulo e mestranda do mesmo programa sob os amparos da CAPES. É pesquisadora nas áreas de moda, feminismo, gênero e sexualidade. E-mail: arcoverde.maira@gmail.com 
Crane (2006) ressalta que as principais mensagens instituídas pelas roupas referem-se aos papéis de gênero $^{2}$ ( sic.) e às maneiras como são considerados ou percebidos pela sociedade. Tanto da distinção de classe quanto das marcas de gênero, o objetivo desses códigos é o mesmo: como uma linguagem não-verbal, eles permitem que se elabore uma interpretação imediata da aparência dx outrx, de maneira a deixar pouca - preferencialmente nenhuma - margem para incertezas. As roupas, inseridas amplamente no contexto binário predominante no ocidente contemporâneo, inscrevem sobre o corpo distintivos a partir dos quais pode-se identificar prontamente o gênero de quem as veste.

Por sua efemeridade intrínseca, a moda muitas vezes é pensada como elemento de transgressão aos padrões impostos em cada época e lugar. Suas frequentes mudanças podem parecer, em uma primeira análise, parte de uma dinâmica que rejeita o velho e enaltece aquilo que é novo, substituindo o que vem antes por algo melhor e mais adequado. Esse trabalho, entretanto, propõe um outro viés: durante todos os séculos desde o surgimento desse mecanismo a que chamamos moda, esse se ocupou com frequência muito maior em reforçar o status quo ao invés de subvertê-lo - ora, a moda, sobretudo no que se refere ao gênero, funcionou e funciona como mais um aparelho do poder para a manutenção das estruturas hierárquicas e normalizadoras. Não sugiro, todavia, que a moda tenha se resumido apenas à essa última função - reconhecendo seu papel como elemento subversivo, chamo a atenção para a necessidade de que ela suporte mais insubordinações que possam, dessa maneira, visibilizar subjetividades silenciadas.

O objetivo deste artigo é problematizar, portanto, as maneiras como se constroem identidades de gênero através da moda, e como essa moda está intimamente ligada à lógica dominante e binária; propondo, por outro lado, que a moda revele com mais ênfase sua faceta subversiva, colocando em prática a desconstrução dos discursos hegemônicos do poder.

\section{Contextualizações e localizações}

Antes de abordar propriamente o assunto do qual tratará este trabalho - a moda e suas relações com o status quo de gênero - abrirei aqui espaço para elucidar conceitos fundamentais que atravessarão o texto, sem os quais o debate se mostraria empobrecido e vazio: sexo, gênero e sexualidade.

Equivocadamente, o pensamento corrente tende a interpretar sexo, gênero e sexualidade como aspectos humanos inexoravelmente ligados a instâncias biológicas tais como a genética, a anatomia e a reprodução, como se tais domínios representassem uma única e indiscutível verdade. Fazse necessário, entretanto, desconstruir esse laço fictício que une os conceitos, caminhando em direção a um pensamento questionador de determinismos e definições biologizantes que apagam as pluralidades de experiências que existem para além das estreitas fronteiras binárias de homemmulher/masculino-feminino/hetero-homo.

\footnotetext{
2 Sobre o equívoco do termo "papéis de gênero", Louro (1997) explica que o conceito acaba se mostrando redutor ou simplista, desconsiderando as múltiplas expressões de masculinidades e feminilidades, bem como as hierarquias de gêneros constituídas nas relações de poder. O gênero neste ensaio será pensado como uma prática discursiva que compõe a identidade dos sujeitos.
} 
O sexo, em sua interpretação mais reconhecida, é visto como determinado pelo material biológico e suas decorrentes diferenças genitais. Enraizada na biologia, essa definição concebia não só as diferenças anatômicas, mas também as diferenças comportamentais entre homens e mulheres como dados fixos e imutáveis - presente, inclusive, na teoria feminista. Linda Nicholson, em Interpretando o gênero (2000, p. 10), aponta que “o 'sexo' permanece na história da teoria feminista como aquilo que fica fora da cultura e da história, sempre a enquadrar a diferença masculino/feminino", ao afirmar que parte do feminismo herdou um sentido no qual o sexo, supostamente um dado biológico, seria uma oposição ao gênero - a ser circunscrito mais adiante, socialmente construído.

Tomo emprestadas as palavras de Foucault: "precisamos verdadeiramente de um verdadeiro sexo?" (FOUCAULT, 1980, p. vii) - ao que, a seguir, ressalta a resposta afirmativa das sociedades modernas ocidentais. Butler, em sua célebre obra Problemas de gênero (2003), questiona:

E o que é, afinal? o "sexo"? É ele natural, anatômico, cromossômico ou hormonal, e como deve a crítica feminista avaliar os discursos científicos que alegam estabelecer tais "fatos" para nós? Teria o sexo uma história? Possuiria cada sexo uma história ou histórias diferentes? Haveria uma história de como se estabeleceu a dualidade do sexo, uma genealogia capaz de expor as opções binárias como uma construção variável? Seriam os fatos ostensivamente naturais do sexo produzidos discursivamente por vários discursos científicos a serviço de outros interesses políticos e sociais? (BUTLER, 2003, p. 25)

Algumas pistas para essas respostas encontram-se no desenvolvimento do conceito de gênero. Este conceito surgiu no seio do movimento feminista, em contraste à noção de que o sexo, concebido como um fenômeno biológico e, portanto, "verdadeiro", não regia as diferenças comportamentais entre homens e mulheres, sendo essas diferenças antes um produto da cultura (NICHOLSON, 2000; PEDRO, 2005). Embora rejeitassem o determinismo biológico, Nicholson (2000) nota que grande parte das teóricas feministas das décadas de 1960 e início de 1970 concordavam que havia de fato distinções biológicas reais entre homens e mulheres, embora nem todas as suas diferenças originassem daquele princípio. O gênero aparece então fundamentado na cultura, embora "não só o 'gênero' não era visto como substituto de 'sexo' como também 'sexo' parecia essencial à elaboração do próprio conceito de 'gênero'. [...] Aqui o biológico foi assumido como a base sobre a qual os significados culturais são constituídos”. (NICHOLSON, 2000, p. 11)

Butler (2003) indica a controvérsia decorrente dessa teoria:

[...] mesmo que os sexos pareçam não problematicamente binários em sua morfologia e constituição [...], não há razão para supor que os gêneros também devam permanecer em número de dois. A hipótese de um sistema binário dos gêneros encerra implicitamente a crença numa relação mimética entre gênero e sexo, na qual o gênero reflete o sexo ou por ele é restrito. (BUTLER, 2003, p. 24)

Não obstante, essa ideia inicial e muito difundida sobre as relações entre sexo e gênero o primeiro como biológico e o último como social e constituído a partir do primeiro, é em si própria problemática por adotar o sexo como algo necessariamente anterior ao gênero e, portanto, pré-discursivo. Butler, em atenta análise, desloca o "sexo natural" de seu estatuto de verdade 
colocando-o como histórica e discursivamente concebido em benefício de interesses políticos e sociais, por consequência se mostrando "tão culturalmente construído como o gênero" (BUTLER, 2003, p. 25). Ao refutar o falso mimetismo exposto anteriormente, a autora articula o gênero como um meio discursivo através do qual o sexo é constituído como fenômeno anterior à cultura, sendo responsável pela produção do sexo como "uma superfície politicamente neutra sobre a qual age a cultura" (BUTLER, 2003, p. 25). Em outras palavras, o sexo como visto em sua acepção mais recorrente é, na verdade, construído pelo gênero.

O terceiro eixo a sustentar essa breve elucidação é o da sexualidade. A sexualidade, como afirmou Foucault (2001), conquista no século XIX posição de máximo interesse aos Estados das sociedades ocidentais, a partir de uma série de transformações culturais, econômicas e políticas que se vinham se desdobrando desde o século anterior. Nesse período, mais precisamente do final do século XIX, os discursos autorizados (essencialmente masculinos) ocuparam-se em produzir uma "verdade" sobre a sexualidade que repousava nos comportamentos de uma sociedade urbana ocidental branca e de classe média, a definir o que era bom ou não, cabível ou não. (LOURO, 2009)

Surge então, nesse cenário, a figura homossexual. A prática anteriormente vista como sodomia, cujxs sujeitxs eram enquadradxs como pecadorxs ou criminosxs reincidentes, adquire uma outra significação - x sujeitx homossexual passou a constituir uma espécie, completamente nova e distinta (FOUCAULT, 2001). De acordo com Louro (2009), "para este tipo de sujeito, haveria que inventar e pôr em execução toda uma sequência de ações: punitivas ou recuperadoras, de reclusão ou de regeneração, de ordem jurídica, religiosa ou educativa”. (LOURO, 2009, p. 88)

Ora, pois se havia surgido uma espécie inteiramente diversa daquilo que era concebido como "normal", qual então seria essa suposta normalidade? Fez-se necessário, portanto, a criação daquela que serviria de parâmetro para o comportamento destoante: a heterossexualidade e x sujeitx heterossexual. Aqui Foucault (2001) é bastante claro ao afirmar que a sexualidade regular (heterossexual) se legitima a partir das sexualidades periféricas, resultando em que uma não poderia viver sem a outra. Sua existência, calcada na criação de um inverso desviante, só pode sêla enquanto também o for aquela que lhe é antagônica.

Ainda assim, a heterossexualidade continua como o polo privilegiado da lógica binária, gozando de um status de verdade e normalidade afirmado e reafirmado cotidianamente nas mais diversas instâncias. Como sustentado por Louro (2009),

[...] reafirma-se o princípio de que os seres humanos nascem como macho ou fêmea e que seu sexo - definido sem hesitação em uma destas duas categorias vai indicar um de dois gêneros possíveis - masculino ou feminino - e conduzirá a uma única forma normal de desejo, que é o desejo pelo sujeito de sexo/gênero oposto ao seu. (LOURO, 2009, p. 89)

Os usos do corpo são permeados por uma série de regras conjugadas ao que se chamou, num primeiro momento, de heterossexualidade compulsória (termo cunhado pela feminista Adrienne Rich ${ }^{3}$ ) 3 RICH, Adrienne. Compulsory heterosexuality and lesbian experience. Signs. Women: Sex and Sexuality, v. 5, n. 4, p. 631-660, Summer 1980. 
e, posteriormente, de heteronormatividade (de Michael Warner ${ }^{4}$ ) - ambos tributários das problematizações levantadas pelos estudos feministas, gays e lésbicos e da Teoria Queer. É nessa imposição de um modelo heterossexual como o "normal" que se consolida o suposto alinhamento entre sexo-gênero-sexualidade como elucidado por Louro (2009).

A heterossexualidade compulsória, segundo Miskolci (2012), é a imposição do modelo de relações - amorosas e/ou sexuais - entre pessoas do sexo oposto como ideal e "normal"; ao passo que a heteronormatividade regula como as pessoas se relacionam, mesmo que sejam do mesmo sexo: "a sociedade ainda exige [...] um estilo de vida que mantém a heterossexualidade como um modelo inquestionável para todos" (MISKOLCI, 2012, p. 45). É na heteronormatividade que se projeta expectativas heterossexuais sobre casais homoafetivos - diferenciação entre "ativxs" e "passivxs"; ou ainda, quem são o "homem" e a "mulher" da relação. Àquelxs que desviam da heteronormatividade, restam a exclusão, a invisibilização, a omissão e, no pior dos casos, a punição - institucional ou não.

Explicados os conceitos que serão essenciais nesse artigo, volto à questão inicial: como a moda se articula com sexo, gênero e sexualidade? O ponto principal e anteriormente citado aborda a moda como mecanismo de legitimação de um presumido alinhamento dos três conceitos segundo uma lógica dicotômica: macho-fêmea, homem-mulher, masculino-feminino. Entre os diversos discursos que constroem essa analogia - médico, educacional, religioso, político, etc.; o discurso indumentário, como parte fundamental da construção de subjetividades, serve também como manobra para produzir e reproduzir aparências e estilos hegemônicos.

Há uma clara fronteira que separa, desde meados do século XIV, as roupas em dois grandes grupos: masculino e feminino - como um dos elementos sobre os quais se manifestam os discursos de "verdade" acerca do gênero, a moda corrobora com a noção de que há uma maneira "correta" de agir, se portar e se vestir nas sociedades ocidentais contemporâneas. Tomando emprestadas as palavras de Berenice Bento (2003): "o gênero adquire vida através das roupas que cobrem o corpo, dos gestos, dos olhares, de uma estilística corporal e estética definida como apropriada". (BENTO, 2003, s/p)

Entretanto, por mais intrincado que possa parecer, é possível pensar que esse próprio sistema normativo carrega em si possibilidades de subversão, e tais possibilidades podem ser exploradas na indumentária - ela também se ocupa, ainda que com menos vigor do que se pensa, da desconstrução de certos discursos uma vez considerados incontestáveis e sólidos: lentamente, tradições puderam ser subvertidas e ressignificadas com o amparo da moda.

\section{Moda: na trama da cultura dominante}

Longe de funcionar apenas como mecanismo de subversão, como já dito, a roupa serve também (e talvez ainda com maior destaque) ao propósito da manutenção da cultura dominante - a aparente

4 WARNER, Michael (Ed.). Fear of a Queer planet: Queer politics and social theory. Minneapolis; London: University of Minnesota Press, 1993. 
insubordinação manifesta em suas mudanças sazonais não é tão extensa quanto se imagina ser. Desde seu surgimento como o fenômeno ao qual nos referimos hoje, a moda produz e reproduz discursos indumentários alinhados aos valores morais, culturais e políticos de sua época. As roupas, como pondera Calanca, e "os objetos com os quais cobrimos o corpo são as formas pelas quais os corpos entram em relação entre si e com o mundo externo". (CALANCA, 2011, p. 17)

Em seu relevante ensaio sobre moda, Simmel (1971) aponta dois mecanismos fundamentais de sua dinâmica: de um lado, o desejo de pertencimento expresso pela imitação de determinados comportamentos do grupo do qual se espera reconhecimento; do outro, o anseio pela distinção, por poder ser uma pessoa singular. Quando se fala no respaldo à cultura dominante, claramente faz-se referência ao primeiro dos mecanismos da moda: a vontade de pertencer ao grupo e dele receber legitimidade dialoga com a outra face desta dinâmica - aquelas pessoas às quais não é conferido o reconhecimento acabam obliteradas e vistas como párias por não atender às exigências. Ao "falhar" em reproduzir a aparência esperada do gênero que lhes foi atribuído, há um rompimento com esse gênero "original" - podendo, muito bem, simbolizar uma traição (ainda que inconsciente) ao presumido determinismo biológico.

Do século XV ao XVII, Silverman (1994) afirma que a roupa mais adornada seria antes uma prerrogativa de estrato social do que de gênero, uma vez que a extravagância no vestuário era um marcador de privilégios e poder aristocráticos. Opondo-se ao viés de classe enfatizado por Silverman, Hollander (2003) considera ser a sexualidade $\mathrm{o}^{5}$ "motor expressivo fundamental" (p. 47) das roupas, visto que elas denotavam antes um caráter masculino ou feminino, para só então servir como expoente de classe e de função/ofício. Cabe aqui considerar que as expressões de gênero na moda se deram e se dão de maneira contingente: pensar em um "masculino" e um "feminino" nas roupas só faz sentido quando se localiza o discurso histórica e culturalmente - a indumentária nas sociedades ocidentais sofreu diversas alterações segundo o período em que se encontravam, quase todas elas (não sem resistência) acabando por ser incorporadas à cultura dominante.

Dito isso, diversxs teóricxs da indumentária (BOUCHER, 2010; CALANCA, 2011; WILSON, 2003) concordam que, durante os dois últimos séculos, a moda feminina ocupou-se em copiar e se inspirar na masculina. É fato que a moda das cortes europeias, em especial durante o século XVII e parte do XVIII e sob forte influência da França, teve sua profusão de detalhes e ornamentos luxuosos encarnados, principalmente, pela indumentária masculina - ainda que fosse alvo da imitação feminina, esta não se equiparava à primeira na exuberância. Se vista sob a ótica contemporânea, a moda masculina desse período incorporava elementos atualmente considerados exclusivos do domínio feminino: maquiagem, perucas, salto alto, calças justas, rendas, bordados, etc. (Figura 1) - em relativamente pouco tempo, podemos perceber a contingência do gênero, muito embora hoje lhe seja conferido o estatuto de pré-discursivo, inato, a-histórico.

5 Vale frisar que o significado que a autora atribui aqui à sexualidade se aproxima mais daquele de gênero presente neste artigo. Como sugere Louro (2009), “[...] temos de reconhecer que sexualidade e gênero estão profundamente articulados, talvez mesmo, muito frequentemente, se mostrem confundidos" (LOURO, 2009, p. 91) 


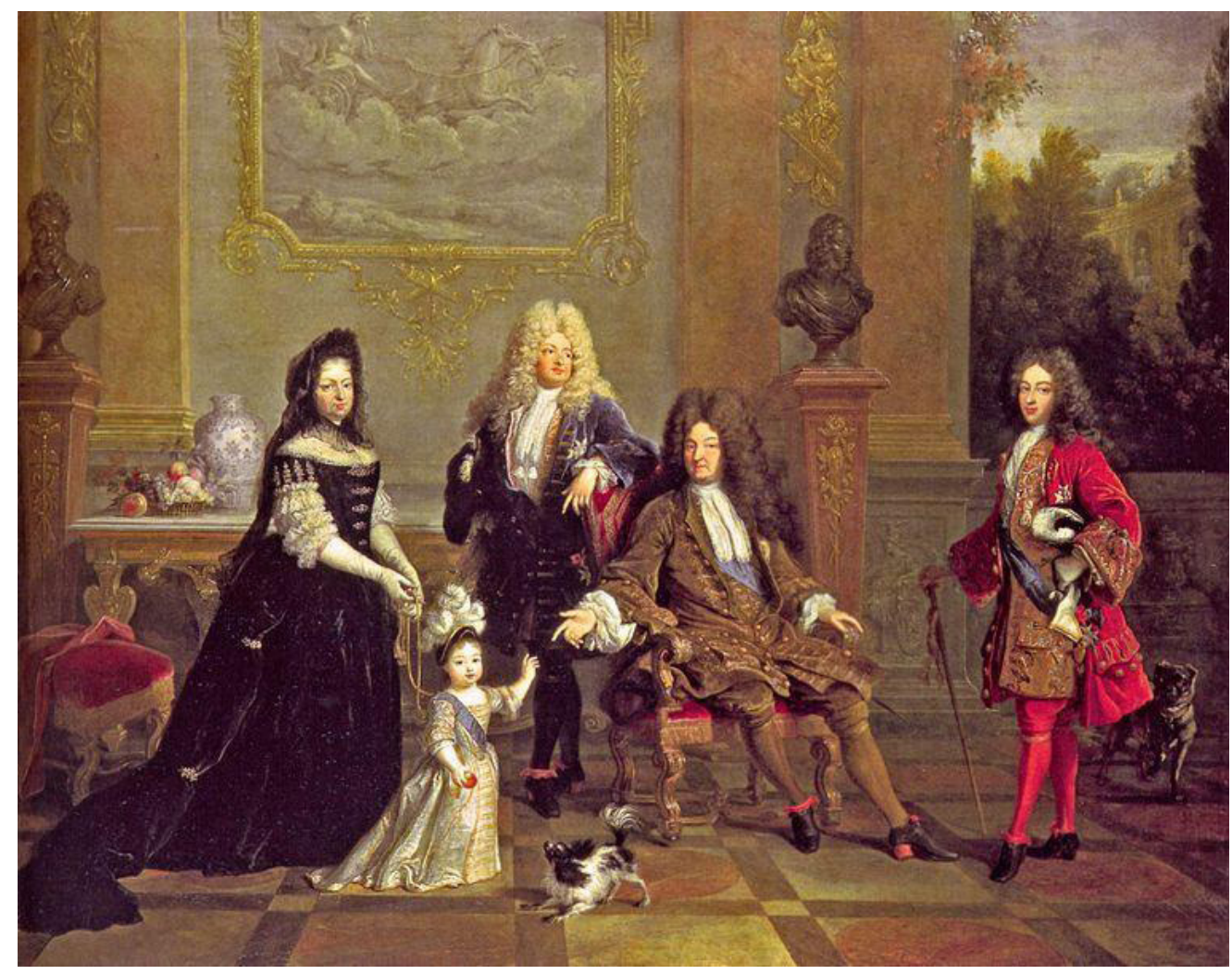

Figura 1 - Luís XIV e seus herdeiros

Autor: Nicolas de Largillière (1711)

Após muita resistência, uma das maiores vitórias das mulheres no que tange ao vestuário foi a adaptação das calças aos seus elementos, democratizando assim um símbolo até então masculino. O movimento tímido que se iniciou com Amelia Bloomer e o traje Bloomer em 1851 (Figura 2), rechaçado pela sociedade conservadora da época, ganhou força nas décadas que se seguiram - contando com o apoio das feministas - e culminou na difusão completa ${ }^{6}$ do uso de calças por mulheres nas décadas de 1960 e 1970.

Trata-se, portanto, de uma corrente irreversível, correspondendo - diversas pesquisas apontam essa tendência - ao desejo mais ou menos consciente da maioria das mulheres de manifestar sua igualdade diante do homem usando a mesma roupa que ele. (BOUCHER, 2010, p. 417)

Uma possível justificativa seria a de que, ao mostrar que seus corpos funcionam exatamente como os dos homens - e, em consequência, seus cérebros, o uso de calças pelas mulheres lhes garantiria a humanidade necessária e plena (HOLLANDER, 2003). A democratização de uma peça de roupa, portanto, não representou para as mulheres apenas mais uma possibilidade indumentária entre as já existentes, mas funcionou como elemento empoderador de toda uma categoria histórica e culturalmente subalternizada.

6 A difusão completa à qual me refiro diz respeito às mulheres das classes privilegiadas. Antes mesmo das calças para mulheres se tornarem aceitáveis para a sociedade em geral, mulheres da classe operária já usavam-nas na Europa, bem como aquelas que viviam nas regiões de fronteira dos Estados Unidos - somente o faziam, entretanto, pois encontravam-se em espaços invisibilizados ou isolados onde não eram submetidas às rígidas normas do vestuário. 


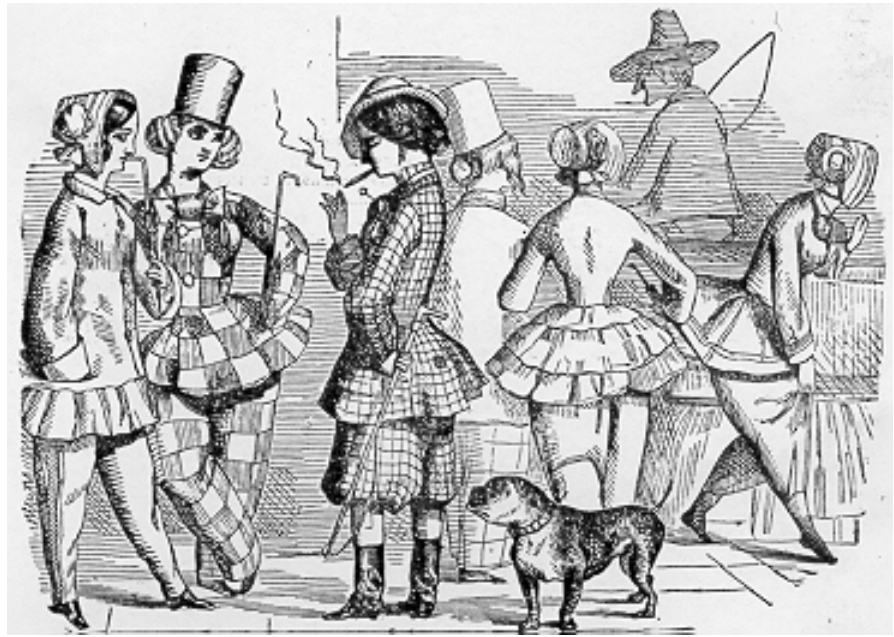

Figura 2 - The Bloomer costume

Fonte: Harper's New Monthly Magazine (1851)

O inverso, todavia, não aconteceu. Sob forte influência religiosa no ocidente, a troca de roupas, sobretudo quando homens vestem roupas consideradas "de mulher", era vista como pecado grave. Embora hoje o domínio da religião não seja tão rigoroso quanto na Idade Média, por exemplo, e o pecado não regule mais os comportamentos como outrora, há a percepção já citada de uma "traição" dos valores e da moral - travestir-se é visto como um ato imoral, obsceno. Culturalmente, sabe-se que os valores hierárquicos do feminino e do masculino na sociedade contemporânea não são equivalentes, uma vez que o segundo é mais valorizado que o primeiro no ocidente. Assim sendo, o fenômeno que compreende homens se vestindo ou se apropriando de certas peças julgadas femininas, por si só, é um fato interessante, dado que o feminino apresenta menor prestígio social que o masculino (VENCATO, 2003). Tal prática, além de dissolver a lógica binária e essencializada, também "desnaturaliza, desestabiliza e desfamiliariza os signos de sexo e gênero". (GARBER, 1997, p. 147, tradução nossa)

Todavia, chegando à última metade do século $\mathrm{XX}$, as subculturas jovens influenciadas por movimentos identitários como o feminista e o gay, começam a rejeitar o modelo único de masculinidade ${ }^{7}$ expressado por meio da roupa desde meados do século XVIII (CRANE, 2006). A inflexibilidade da moda masculina iniciada dois séculos antes, com a supressão do traje de corte e da roupa como elemento distintivo de classe social ${ }^{8}$, começa a perder força e ceder lugar a formas mais autênticas de se vestir dentro da cultura jovem.

7 Em que pese a mudança proporcionada pelas lutas identitárias (em especial o movimento gay), é importante lembrar que, dentro deste mesmo movimento, houve grupos cujo discurso indumentário exacerbava a masculinidade hegemônica da época ao ponto de exibir uma ultramasculinidade - esses indivíduos foram, inclusive, apelidados de clones (WILSON, 2003), dada sua aspiração a um ideal heternormativo de masculinidade.

8 Desde o fim do século XVIII, a roupa masculina vem se simplificando drasticamente - a Inglaterra começa a ser o referencial de elegância, e já no século XIX a moda usada pelos homens não carrega praticamente nenhuma semelhança com o áureo período de exuberância da corte: segundo Boucher (2010), "mesmo antes de 1780, a roupa começava a não ser mais tão estreitamente ligada quanto no passado à noção de classe social” (BOUCHER, 2010, p. 313). O traje sóbrio do século XIX, que perdurou até a metade do século XX, endureceu a aparência dos homens e norteou o conceito de masculinidade na aparência durante um longo período. À essa mudança no vestuário masculino (da extrema opulência à austera monotonia), Flügel, em sua obra A Psicologia das Roupas (1966) dá o nome de a "Grande Renúncia Masculina”. Desde então, a roupa masculina atravessou os séculos sem grandes alterações em sua estrutura, situação que só começou a mudar com a chegada do século XX e sua profusão de subculturas. (HOLLANDER, 2003; SILVERMAN, 1994) 
À medida que no século XVIII começou-se a caminhar em direção à uma indumentária mais universal no sentido de menores e menos evidentes demarcações sociais (no vestuário masculino), ao mesmo tempo começam a se formar nas roupas noções de masculinidade e feminilidade que permeiam as sociedades ocidentais até os dias de hoje: cobre-se os corpos masculinos com uma vestimenta austera - e por que não dizer, monótona?, ao passo em que os corpos femininos tornamse os portadores das mudanças e efemeridade da moda.

É possível notar que, muito embora a cultura jovem das décadas de 1960 e 1970 tenha exercido grande influência subversiva na moda masculina, há ainda uma forte tradição de se considerar vestidos e saias unicamente associados ao gênero feminino, impondo barreiras à sua absorção pelos homens ao contrário do que aconteceu com as calças e sua incorporação ao vestuário das mulheres no mesmo período. Aqui localiza-se a principal resistência da moda abordada neste texto - a transgressão da norma no vestuário masculino encontra cada vez mais adeptxs, o que pode ser visto especialmente no trabalho de estilistas e marcas internacionais e nacionais ilustrados a seguir.
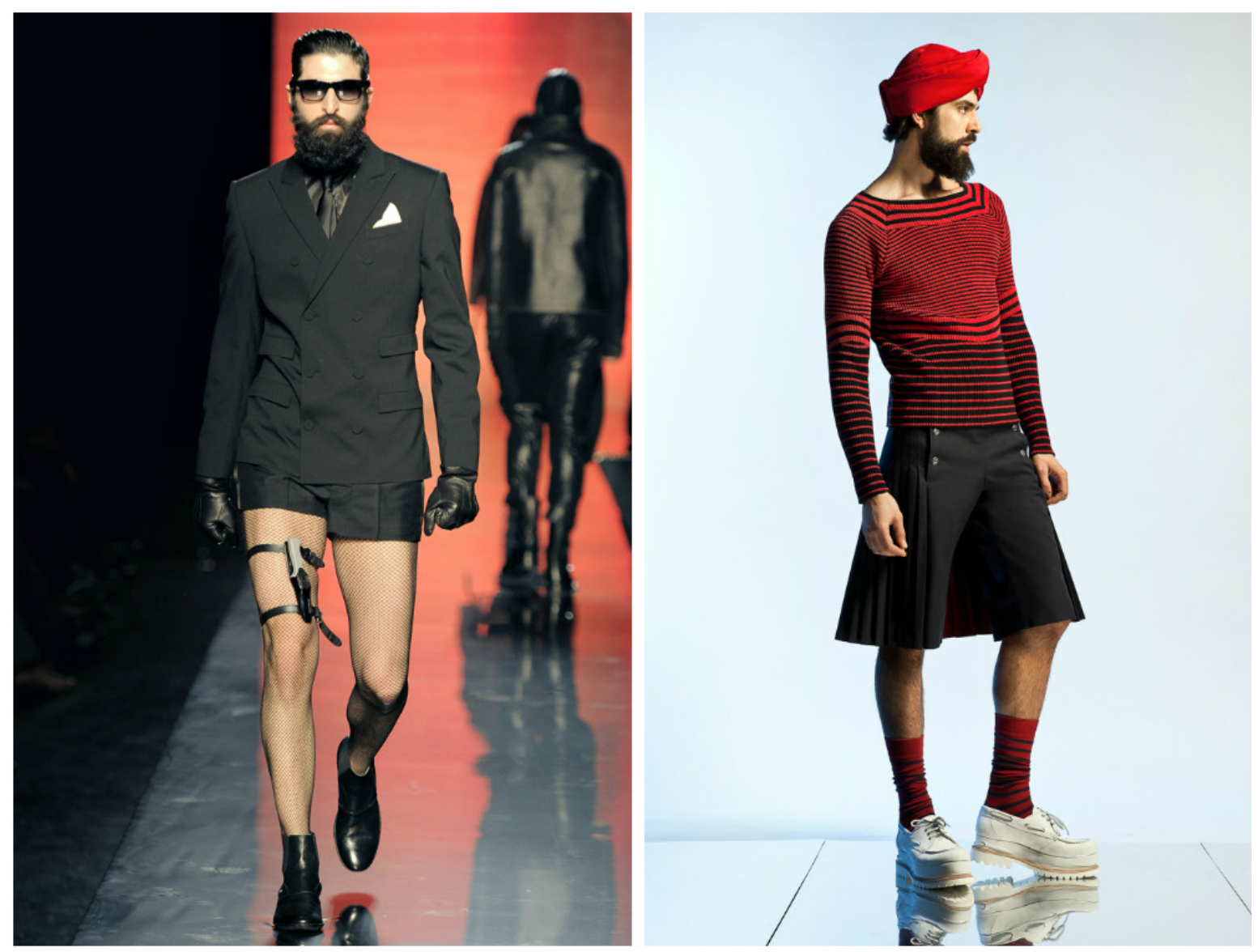

Figura 3 - Jean Paul Gaultier Men - Outono 2011/ Primavera 2013

Fotografia: Yannis Vlamos (esq.) e Rainer Torrado (dir.)

Jean Paul Gaultier, enfant terrible da moda francesa, ficou conhecido por lançar e promover o uso de saias para homens (Figura 3), além de incorporar à moda masculina elementos amplamente percebidos como femininos no Ocidente. É importante destacar que a subversão vestimentar masculina não se dá necessária e exclusivamente pelo uso das saias ou vestidos (direita), uma vez 
que sua austeridade secular também é expressa nas cores monocromáticas, formas rígidas e em quais partes do corpo estão cobertas e quais delas estão à mostra. Como pode-se observar na imagem da esquerda, o comprimento dos shorts - bem acima do joelho - e as meias arrastão compõem um look deslocado daquele que se cristalizou desde o século XVIII como a roupa masculina por excelência, com as pernas totalmente cobertas ou descobertas apenas do joelho para baixo, sem que estas insinuassem qualquer sensualidade. A exibição das pernas adornadas pelas meias arrastão aludem a uma imagem convencionada como feminina e seu discurso de objetificação/sexualização de um corpo ao mesmo tempo vestido e desnudo.
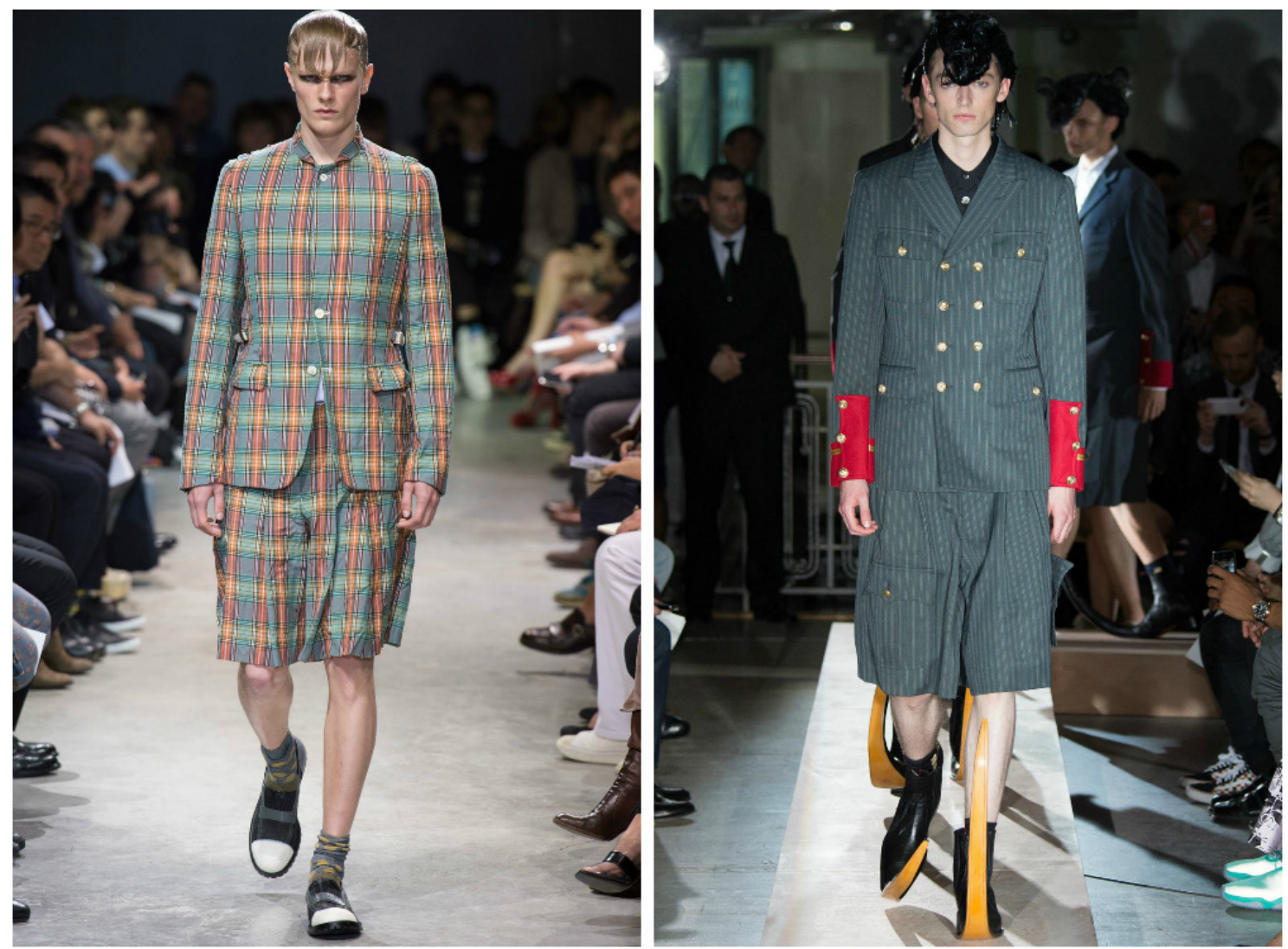

Figura 4 - Comme des Garçons Men - Primavera 2014/ Primavera 2015

Fotografia: Yannis Vlamos

A marca japonesa Comme des Garçons, fundada pela estilista Rei Kawakubo, inicia sua linha masculina em 1978 e apresenta em suas coleções a desconstrução e ressignificação dos corpos por meio de modelagens inusitadas e formas muitas vezes assimétricas. Muitos de seus desfiles são marcados pela presença da alfaiataria masculina associada à elementos da moda feminina, como estampas florais, saias e vestidos. Em duas de suas recentes apresentações (Figura 4), a Comme des Garçons apresenta uma nova ideia de homem, contestando a estabilidade forçada de um discurso indumentário quase compulsório lançando mão de saias em estampas de cores pastéis (esquerda), frequentemente associadas à uma ideia de docilidade e fragilidade femininas, e descaracterizando o uniforme militar (direita) ao inseri-lo em um contexto pacífico ${ }^{9}$, subvertendo a lógica que constrói os homens como belicosos e violentos.

9 Nesta última coleção, algumas peças apresentaram elementos textuais que reforçavam o espírito anti-guerra transmitido, como "Soldier of Peace", "Peace, Love, Empathy" e "Anything war can do, peace can do better" ("Soldado da paz", "Paz, Amor, Empatia" e "O que quer que a guerra possa fazer, a paz pode fazer melhor", em tradução livre). 

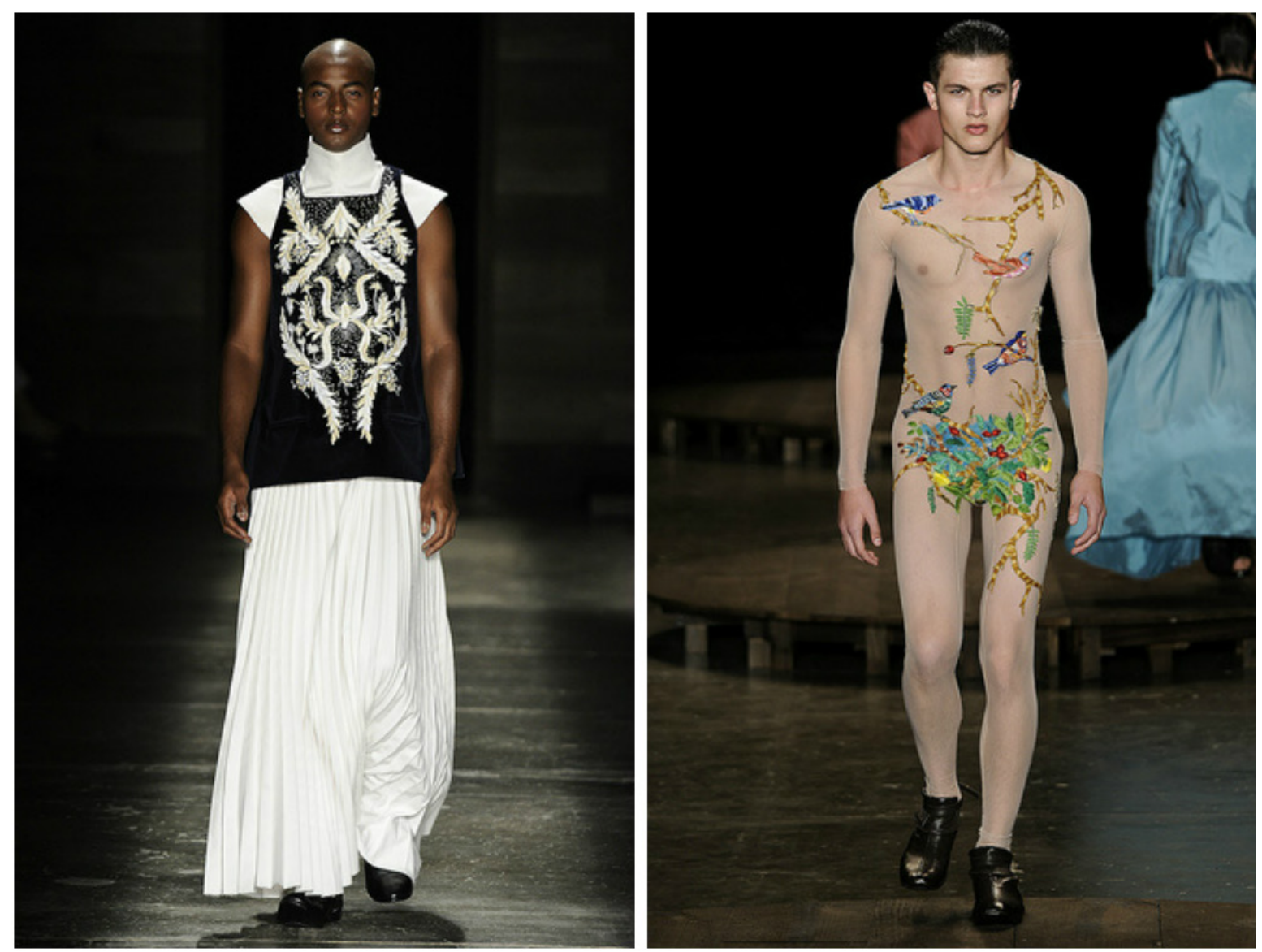

Figura 5 - João Pimenta - Inverno 2011/ Verão 2012

Fotografia: Zé Takahashi

Voltando-se para o Brasil, encontramos em João Pimenta umx dxs principais representantes desta (des)construção das masculinidades e insubordinação ao gênero essencializado que também são expressas por meio da roupa. $\mathrm{O}$ estilista mineiro começou a carreira na moda feminina, mudando seu foco ao perceber que diversos homens iam à sua loja justamente para comprar peças que não faziam parte do restrito guarda-roupa masculino - desde então, Pimenta faz experimentações com as possibilidades de expressão permitidas pela roupa, fugindo aos limites da convenção hegemônica. Nas imagens do exemplo (Figura 5), a saia longa plissada (esquerda) confere fluidez e leveza aos movimentos, característica pouco comum às tradicionais roupas masculinas, enquanto o body transparente (direita) revela os contornos de um corpo masculino sensual e erotizado. Ambos os looks atraem o olhar para a exuberância dos bordados, monocromáticos ou multicoloridos, que devolvem à roupa masculina a riqueza de detalhes e ornamentação abandonadas há mais de dois séculos.

Ainda que a moda das passarelas ofereça e incentive novas possibilidades do vestir, a sociedade de maneira geral ainda guarda muitas reservas especialmente no que diz respeito à desconstrução da estrutura binária reiterada e reafirmada pela roupa. O que é visto como "conceitual" e como expressão do potencial criativo dxs estilistas nas apresentações encontra no cotidiano das ruas a resposta fria, desqualificante e por vezes agressiva de uma sociedade que ainda luta, ora para livrarse, ora para manter tradições conservadoras e heteronormativas. 


\section{Subversão da norma, ressignificação das práticas desviantes}

Como problematizado anteriormente, o papel da moda foi muito importante na manutenção do status quo de gênero em diferentes épocas. Entretanto, as militâncias feminista e gay da década de 1960 contribuíram fundamentalmente com maiores liberdades e possibilidades àquelas pessoas que possuem perspectivas insubordinadas em relação ao que se convencionou como a regra, refletidas nas ruas e passarelas contemporâneas. De lá pra cá, a história presenciou a fragmentação daqueles movimentos, dando origem a diversas vertentes cuja luta é também o empoderamento da identidades abjetas ${ }^{10} \mathrm{e}$ conferindo agência às pessoas subalternizadas.

Sabemos que o suposto caráter pré-discursivo do sexo é uma falácia, como pudemos observar em Butler (2003): é possível que o sexo sempre tenha sido o gênero, uma vez que esse último produz o primeiro como sendo anterior à cultura e à história. Ora, se podemos compreender ambos como práticas discursivas, partimos então para um conceito chave na teoria butleriana: a performatividade de gênero. Segundo a autora, os corpos participam ativamente da construção e reiteração das normas de gênero percebidas, através de repetições de atos que se supõem naturais. Nas palavras de Berenice Bento:

A partir das reiterações contínuas, realizadas mediante interpretações em atos das normas de gênero, os corpos adquirem sua aparência de gênero, assumindo-o em uma série de atos que são renovados, revisados e consolidados no tempo. É isso que Butler chamará de performatividades de gênero. (BENTO, 2006, p. 87)

As performatividades, no entanto, são múltiplas e podem estar em maior ou menor sintonia com o que se espera desses corpos. Aqui entramos no campo da subversão - para Bento (2006), "vestir-se é um dos atos performáticos mais carregados de significados para a construção das performances dos gêneros" (BENTO, 2006, p. 179). A moda, como uma linguagem do corpo (CALANCA, 2011), pode ser palco de insubordinações às regras impostas - é dentro do mecanismo mesmo de controle que se encontram frestas para retificar preceitos que nos colocam como dados. Nas palavras de Crane:

Por um lado, as roupas da moda personificam os ideais e valores hegemônicos de um período determinado. Por outro, as escolhas de vestuário refletem as formas pelas quais os membros de grupos sociais e agrupamentos de diversos níveis sociais veem a si mesmos em relação aos valores dominantes. (CRANE, 2006, p. 454)

Repetir atos performáticos do vestir de maneiras inesperadas não só é uma maneira encontrada para manifestar singularidade e diferença - retomando Simmel (1971), mas também é um ato político: é deixar de curvar-se a uma lógica opressiva do poder que investe nos corpos e práticas desviantes um caráter de anormalidade e ressignificar o próprio conceito histórica e culturalmente construído de normalidade. Ao mesmo tempo em que se arrisca sofrer violências simbólicas, coloca-se em evidência, recusa-se a submissão alçando a diferença à condição de real e necessária às mudanças que se espera ver:

10 Podemos citar, entre estas, o movimento queer, os Estudos Pós-Coloniais, o feminismo das mulheres negras, o transfeminismo. 
[...] uma política da diferença emerge como crítica do multiculturalismo e da retórica da diversidade, afirmando a necessidade de ir além da tolerância da inclusão mudando a cultura como um todo por meio da incorporação da diferença, do reconhecimento do Outro como parte de todos nós. (MISKOLCI, 2012, p. 51, grifo nosso)

A moda, pois, deve estar engajada nesta mudança da cultura e das relações de poder, como já o fez antes, impondo-se ao lado dos novos movimentos identitários contra a limitação dos corpos e transformando-se por meio das diferenças. Estender seu caráter subversivo ao gênero é questionar e tensionar a própria lógica binária (homem-mulher, masculino-feminino, hetero-homo) e heteronormativa, ressignificar o abjeto e se abrir às experiências subalternizadas como veículo de transformação social, da mesma maneira que Miskolci (2012) propõe à educação.

\section{Referências}

BENTO, Berenice. Transexuais, corpos e próteses. In: Labrys Estudos Feministas, n.4, ago./dez. 2003. Disponível em: < http://www.tanianavarroswain.com.br/labrys/labrys4/textos/berenice1. $\underline{\text { htm }}>$

. A reinvenção do corpo: sexualidade e gênero na experiência transexual. Rio de Janeiro: Garamond, 2006.

BOUCHER, François. História do vestuário no Ocidente. São Paulo: Cosac Naify, 2010.

BUTLER, Judith. Problemas de gênero: Feminismo e subversão da identidade. Rio de Janeiro: Civilização Brasileira, 2003.

CALANCA, Daniela. História social da moda. São Paulo: Editora Senac, 2011.

CRANE, Diana. A moda e seu papel social: classe, gênero e identidade das roupas. $2^{\text {a }}$ edição. São Paulo: Editora Senac, 2006.

FOUCAULT, Michel. (Introduction to) Herculine Barbin. Nova Iorque: Pantheon, p. vii-xvii, 1980.

Graal, 2001. . História da sexualidade I: a vontade de saber. 14a edição. Rio de Janeiro: Edições

GARBER, Marjorie. Vested Interests: Cross-dressing and cultural anxiety. Nova Iorque: Routledge, 1997.

HOLLANDER, Anne. O sexo e as roupas: a evolução do traje moderno. Rio de Janeiro: Rocco, 2003.

LOURO, Guacira Lopes. Gênero, sexualidade e educação: uma perspectiva pós-estruturalista. Petrópolis: Vozes, 1997.

. Heteronormatividade e homofobia. In: JUNQUEIRA, Rogério Diniz (Org.). Diversidade sexual na educação: problematizações sobre a homofobia nas escolas. Brasília: Ministério da Educação, Secretaria da Educação Continuada, Alfabetização e Diversidade, UNESCO, 2009.

MISKOLCI, Richard. Teoria Queer: um aprendizado pelas diferenças. $2^{\text {a }}$ edição. Belo Horizonte: Autêntica Editora, 2012.

NICHOLSON, Linda. Interpretando o gênero. In: Revista Estudos Feministas. Florianópolis, v.8, n.2, p. 9-41, 2000.

PEDRO, Joana Maria. Traduzindo o debate: o uso da categoria gênero na pesquisa histórica. In: 
História. São Paulo, v.24, n.1, p. 77-98, 2005.

SILVERMAN, Kaja. Fragments of a fashionable discourse. In: BENSTOCK, Shari; FERRISS, Suzanne (Org.). On fashion. New Brunswick: Rutgers University Press, 1994.

SIMMEL, George. Fashion. In:

. On individuality and social forms. Chicago: The University of Chicago Press, 1971. Cap. 19, p. 294-323.

VENCATO, Anna Paula. Confusões e estereótipos: O ocultamento de diferenças na ênfase de semelhanças entre transgêneros. Cadernos AEL, Vol. 10, No. 18/19, 2003.

WILSON, Elizabeth. Adorned in dreams: fashion and modernity. Londres: I. B. Tauris, 2003. 